PAPER

\title{
Objective B wave analysis in 55 patients with non- communicating and communicating hydrocephalus
}

\author{
H Stephensen, N Andersson, A Eklund, J Malm, M Tisell, C Wikkelsö
}

J Neurol Neurosurg Psychiatry 2005;76:965-970. doi: 10.1136/jnnp.2004.039834

See end of article for authors' affiliations

.....................

Correspondence to: Dr Magnus Tisell,

Hydrocephalus Research

Unit, Institute of Clinical

Neuroscience,

Sahlgrenska University

Hospital, Göteborg

University, 41345

Göteborg, Sweden:

magnus.tisell@vgregion.se

Received 22 February 2004

In revised form

25 September 2004

Accepted 10 October 2004

\begin{abstract}
Background: B waves, slow and rhythmic oscillations in intracranial pressure (ICP), are claimed to be one of the best predictors of outcome after surgery for normal pressure hydrocephalus (NPH).

Object: To determine the relation between the percentage of $B$ waves and outcome in patients with hydrocephalus, and also the diurnal variation of $B$ waves.

Methods: ICP and patient behaviour were recorded overnight (17 to 26 hours) in 29 patients with noncommunicating hydrocephalus and 26 with NPH. The B wave activity, measured with an amplitude threshold of $0.5,0.75,1.0,1.5,2.0,3.0$, and $5.0 \mathrm{~mm} \mathrm{Hg}$, was estimated as the percentage of total monitoring time (\% B waves) using a computer algorithm, and correlated with postoperative outcome, defined as changes in 12 standardised symptoms and signs.

Results: There was no linear correlation between improvement after surgery in the 55 patients and total $\%$ B waves, but a correlation was found between improvement and \% B waves during sleep $(r=0.39$, $p=0.04$ ). The percentage of $B$ waves was the same during sleep and wakefulness, and patients with NPH had the same proportion of $B$ waves as the non-communicating patients.

Conclusions: $\mathrm{B}$ waves are commonly observed in patients with both communicating and noncommunicating hydrocephalus, but are only weakly related to the degree of postsurgical improvement.
\end{abstract}

B waves, which are slow and rhythmic oscillations in the intracranial pressure (ICP), are defined as periods of 0.5 to 2 minutes with an increase in pressure amplitude from discernible up to $50 \mathrm{~mm} \mathrm{Hg} .{ }^{1}$ The physiological mechanisms behind the $\mathrm{B}$ waves are still obscure. ${ }^{2-4}$ $\mathrm{B}$ waves are frequent in hydrocephalus ${ }^{5-7}$ but are also reported in non-hydrocephalic patients ${ }^{12}$ and in healthy individuals. ${ }^{8}$

Several reports have indicated that the frequent occurrence of B waves predicts a positive outcome to shunt surgery. ${ }^{56910}$ However, as the analyses of the B waves in these studies were undertaken visually and there were limitations to the study design, the predictive value of $\mathrm{B}$ wave analysis is still disputed. Eklund et al recently presented a computerised method for analysis of B waves. ${ }^{11}$ They found a correlation coefficient of $r=0.74$ between visual interpretation and the computerised analysis. ${ }^{11}$

Improved diagnostic and predictive methods in hydrocephalus are needed. ${ }^{12}$ We evaluated the predictive value of $\mathrm{B}$ waves using the technique developed by Eklund et al on patients with communicating and non-communicating hydrocephalus who underwent ICP recordings at our hydrocephalus research unit.

The specific aims of our study were to determine the relation between the proportion of B waves and the outcome of shunt surgery or third ventriculostomy; to compare the percentage of $\mathrm{B}$ waves during sleep and wakefulness; and to compare the percentage of $\mathrm{B}$ waves in communicating and non-communicating hydrocephalus.

\section{METHODS \\ Patients}

Between 1995 and 2000, 142 patients had surgery for hydrocephalus in our unit. The diagnosis was based on a typical clinical picture and enlarged ventricles (Evan's index $>0.30$ ). Sixty three of these patients underwent overnight ICP recording (not done in the remaining patients because of limited resources, patient refusal, or medical reasons).
Of these 63 patients, eight were excluded because their ICP recordings were unsuccessful (four because of malfunctioning pressure sensors, two because of cerebrospinal fluid (CSF) leakage, and two because they became agitated during the recording. Thus the study population consisted of 55 patients ( 29 with non-communicating hydrocephalus, 13 with idiopathic normal pressure hydrocephalus (INPH), and 13 with secondary normal pressure hydrocephalus). Age, sex, and aetiology are given in detail in table 1.

Patients were diagnosed as "non-communicating" if radionuclide cisternography showed no retrograde ventricular filling ${ }^{13}$ and magnetic resonance imaging (MRI) indicated obstructed outflow from any of the ventricles. NPH was diagnosed when there was a patent aqueduct on MRI (often flow void signal) and retrograde filling of the ventricles on radionuclide cisternography.

The patients with non-communicating hydrocephalus underwent endoscopic third ventriculostomy or shunt surgery. Patients with remaining or relapsing hydrocephalus symptoms in spite of a patent ventriculostomy were offered secondary shunt surgery. All patients with NPH were operated on with a CSF shunt.

The valves used were Sophy ${ }^{\mathrm{TM}}$ programmable valves (Sophysa, Orsay Cedex, France), Delta ${ }^{\mathrm{TM}}$ shunts, and Strata $^{\mathrm{TM}}$ programmable valves (Medtronic PS Medical, Santa Barbara, California, USA).

The Göteborg University ethics committee approved the study, and informed consent was obtained from the patients and their relatives.

\section{Preoperative and postoperative evaluation}

Patients completed a clinical test battery and MRI or computed tomography was carried out preoperatively and three months postoperatively. If no improvement was observed in spite of adjustment of the valve to low pressure,

Abbreviations: ICP, intracranial pressure; $\mathrm{NPH}$, normal pressure hydrocephalus 
Table 1 Demographic and outcome data after endoscopic third ventriculostomy or shunt surgery in 29 patients with noncommunicating hydrocephalus and in 26 patients with normal pressure hydrocephalus

\begin{tabular}{|c|c|c|c|c|c|c|c|c|}
\hline Type & $\begin{array}{l}\text { Age } \\
\text { (years) }\end{array}$ & Sex & Aetiology & Psychometric index & $\begin{array}{l}\text { Wakefulness } \\
\text { index }\end{array}$ & Gait index & $\begin{array}{l}\text { Balance } \\
\text { index }\end{array}$ & $\begin{array}{l}\text { Overall } \\
\text { improvement } \\
\text { (MoD) }\end{array}$ \\
\hline Non-comm & 19 & $M$ & AS & -0.63 & 0.00 & 0.01 & 0.00 & -0.12 \\
\hline Non-comm & 31 & $\mathrm{~F}$ & AS & -0.13 & -0.26 & 0.00 & 0.00 & -0.08 \\
\hline Non-comm & 44 & $M$ & AS & -0.10 & 0.00 & -0.01 & 0.00 & -0.02 \\
\hline Non-comm & 51 & $M$ & AS & 0.05 & 0.01 & 0.00 & 0.00 & 0.01 \\
\hline Non-comm & 16 & $\mathrm{~F}$ & AS & 0.00 & 0.00 & 0.02 & 0.00 & 0.00 \\
\hline Non-comm & 73 & $\mathrm{~F}$ & AS & -0.24 & 0.00 & 0.01 & 0.25 & 0.00 \\
\hline Non-comm & 20 & $\mathrm{~F}$ & FVOB & 0.20 & -0.07 & 0.00 & 0.00 & 0.03 \\
\hline Non-comm & 50 & $\mathrm{~F}$ & AS & -0.15 & 0.30 & 0.01 & 0.00 & 0.03 \\
\hline Non-comm & 49 & $M$ & AS & 0.65 & 0.00 & -0.01 & 0.00 & 0.13 \\
\hline Non-comm & 65 & $M$ & AS & 0.29 & -0.04 & 0.14 & 0.00 & 0.08 \\
\hline Non-comm & 54 & $M$ & AS & 0.57 & 0.00 & 0.00 & 0.00 & 0.11 \\
\hline Non-comm & 65 & $\mathrm{~F}$ & AS & 0.25 & 0.06 & 0.26 & 0.00 & 0.11 \\
\hline Non-comm & 20 & $\mathrm{~F}$ & AS & -0.10 & 0.65 & 0.03 & 0.00 & 0.11 \\
\hline Non-comm & 51 & $M$ & FVOB & 0.54 & 0.33 & 0.15 & 0.00 & 0.20 \\
\hline Non-comm & 49 & $M$ & AS & 0.33 & 0.66 & 0.18 & 0.00 & 0.23 \\
\hline Non-comm & 56 & $M$ & AS & 0.49 & 0.59 & 0.15 & 0.00 & 0.25 \\
\hline Non-comm & 61 & $\mathrm{~F}$ & FVOB & 0.87 & 0.30 & 0.11 & 0.00 & 0.25 \\
\hline Non-comm & 39 & $\mathrm{~F}$ & FVOB & 0.77 & & 0.24 & 0.00 & 0.25 \\
\hline Non-comm & 29 & $M$ & AS & 0.26 & -0.01 & 0.15 & 1.15 & 0.31 \\
\hline Non-comm & 48 & $M$ & AS & 0.78 & 0.13 & 0.01 & 1.48 & 0.48 \\
\hline Non-comm & 22 & $\mathrm{~F}$ & AS & 0.70 & 0.30 & 0.03 & 1.24 & 0.45 \\
\hline Non-comm & 71 & $M$ & AS & 0.76 & -0.10 & 0.59 & 1.03 & 0.46 \\
\hline Non-comm & 75 & $\mathrm{~F}$ & AS & 0.41 & 0.33 & 0.31 & 1.24 & 0.46 \\
\hline Non-comm & 63 & $\mathrm{~F}$ & AS & 0.40 & 0.10 & 0.68 & 1.24 & 0.48 \\
\hline Non-comm & 75 & $M$ & AS & 0.43 & 0.02 & 0.55 & 1.65 & 0.64 \\
\hline Non-comm & 67 & $M$ & AS & 0.16 & 0.77 & 0.78 & 1.24 & 0.59 \\
\hline Non-comm & 54 & $M$ & AS & 0.64 & 0.86 & 0.31 & 2.31 & 0.82 \\
\hline Non-comm & 53 & $\mathrm{~F}$ & FMS & 0.40 & 0.30 & 1.13 & 2.27 & 0.82 \\
\hline Non-comm & 71 & $M$ & AS & 1.00 & 1.62 & 0.90 & 2.31 & 1.16 \\
\hline NPH & 79 & $\mathrm{~F}$ & INPH & -0.14 & 0.09 & -0.11 & -2.06 & -0.44 \\
\hline $\mathrm{NPH}$ & 47 & $\mathrm{~F}$ & INPH & 0.18 & 0.21 & 0.05 & 0.00 & 0.09 \\
\hline $\mathrm{NPH}$ & 68 & $\mathrm{~F}$ & INPH & -0.10 & 0.46 & 0.30 & 0.00 & 0.13 \\
\hline $\mathrm{NPH}$ & 77 & $M$ & INPH & 0.00 & 0.00 & 0.13 & 0.62 & 0.15 \\
\hline $\mathrm{NPH}$ & 63 & $\mathrm{~F}$ & SAH & -0.03 & -0.10 & 0.18 & 0.62 & 0.13 \\
\hline $\mathrm{NPH}$ & 64 & $\mathrm{~F}$ & INPH & -0.09 & -0.01 & 0.49 & 0.62 & 0.20 \\
\hline $\mathrm{NPH}$ & 73 & $\mathrm{~F}$ & INPH & 0.42 & 0.35 & 0.17 & 0.21 & 0.23 \\
\hline $\mathrm{NPH}$ & 62 & $M$ & post-op & 0.44 & 0.00 & 0.66 & 0.00 & 0.22 \\
\hline $\mathrm{NPH}$ & 40 & $M$ & $\mathrm{SAH}$ & 0.38 & 1.10 & 0.03 & 0.00 & 0.30 \\
\hline $\mathrm{NPH}$ & 58 & $\mathrm{~F}$ & INPH & 0.31 & 0.68 & 0.30 & 0.00 & 0.26 \\
\hline NPH & 67 & $M$ & INPH & -0.49 & 0.08 & 0.38 & 1.44 & 0.28 \\
\hline $\mathrm{NPH}$ & 80 & $M$ & INPH & 0.91 & 0.06 & 0.72 & 0.00 & 0.34 \\
\hline $\mathrm{NPH}$ & 63 & $\mathrm{~F}$ & SAH & 0.40 & 0.77 & 0.30 & 0.62 & 0.42 \\
\hline NPH & 77 & $\mathrm{~F}$ & INPH & 0.72 & 0.77 & -0.16 & 0.58 & 0.38 \\
\hline $\mathrm{NPH}$ & 78 & $\mathrm{~F}$ & INPH & 0.60 & 1.22 & 0.66 & 0.00 & 0.50 \\
\hline $\mathrm{NPH}$ & 74 & $M$ & INPH & 0.14 & 0.47 & 0.28 & 1.65 & 0.51 \\
\hline NPH & 68 & $\mathrm{~F}$ & INPH & -0.04 & 0.36 & 1.60 & 0.62 & 1.08 \\
\hline NPH & 75 & $M$ & trauma & 0.32 & 0.00 & 0.56 & 2.27 & 0.63 \\
\hline $\mathrm{NPH}$ & 65 & $M$ & trauma & 0.55 & 0.23 & 0.57 & 2.43 & 0.76 \\
\hline $\mathrm{NPH}$ & 73 & $M$ & SAH & 0.71 & 0.08 & 1.52 & 2.06 & 0.87 \\
\hline $\mathrm{NPH}$ & 69 & $M$ & SAH & 0.58 & 0.71 & 1.13 & 1.86 & 1.43 \\
\hline NPH & 62 & $\mathrm{~F}$ & SAH & 0.88 & 0.97 & 0.91 & 2.27 & 1.01 \\
\hline NPH & 56 & $\mathrm{~F}$ & SAH & 1.48 & 2.69 & 0.66 & 0.41 & 1.62 \\
\hline $\mathrm{NPH}$ & 53 & $\mathrm{~F}$ & SAH & 2.07 & 2.32 & 0.00 & & 1.10 \\
\hline $\mathrm{NPH}$ & 72 & $M$ & SAH & 1.63 & 0.77 & 2.23 & 2.47 & 2.00 \\
\hline $\mathrm{NPH}$ & 57 & $M$ & SAH & 1.57 & 0.95 & 2.65 & 2.43 & 1.87 \\
\hline
\end{tabular}

The aetiology of the non-communicating patients was classified as aqueductal stenosis, fourth ventricle oufflow blockage, and foramen of Monro stenosis. The aetiology of the NPH patients was classified as idiopathic, subarachnoid haemorrhage, post-traumatic, or postoperative after tumour surgery. The clinical outcome after surgery is reported as scores on psychometric, wakefulness, gait, and balance indices. The overall postoperative improvement is expressed as the mean of the differences between preoperative and postoperative scores on the four indices.

AS, aqueductal stenosis; FMS, foramen of Monro stenosis; FVOB, fourth ventricle oufflow blockage; INPH, idiopathic normal pressure hydrocephalus; non-comm, non-communicating; MoD, mean of differences; NPH, normal pressure hydrocephalus; $\mathrm{SAH}$, subarachnoid haemorrhage.

the shunt system was checked by a shunt function test ${ }^{15} 16$ and in case of dysfunction was surgically corrected. The postoperative investigation was postponed until three months after the latest corrective surgery.

Patients who initially underwent a third ventriculostomy and who later received a CSF shunt were finally registered three months after the shunt operation.

\section{Clinical test battery}

For an accurate description of the preoperative symptoms and postoperative improvement, we recorded 12 clinical variables. This test battery has been described previously in detail. ${ }^{17}{ }^{18}$ We have shown that these variables improve significantly after shunt surgery or third ventriculostomy in patients with both communicating and non-communicating hydrocephalus. ${ }^{17-19}$

The variables were standardised to enable direct comparisons of values with different numerical scales. ${ }^{15}{ }^{20}$ Indices of psychometric performance (Bingley's visual memory test; identical forms test; mini-mental state examination score), gait ability (general assessment of gait; walking (number of steps and time in seconds); climbing steps (in seconds)), 

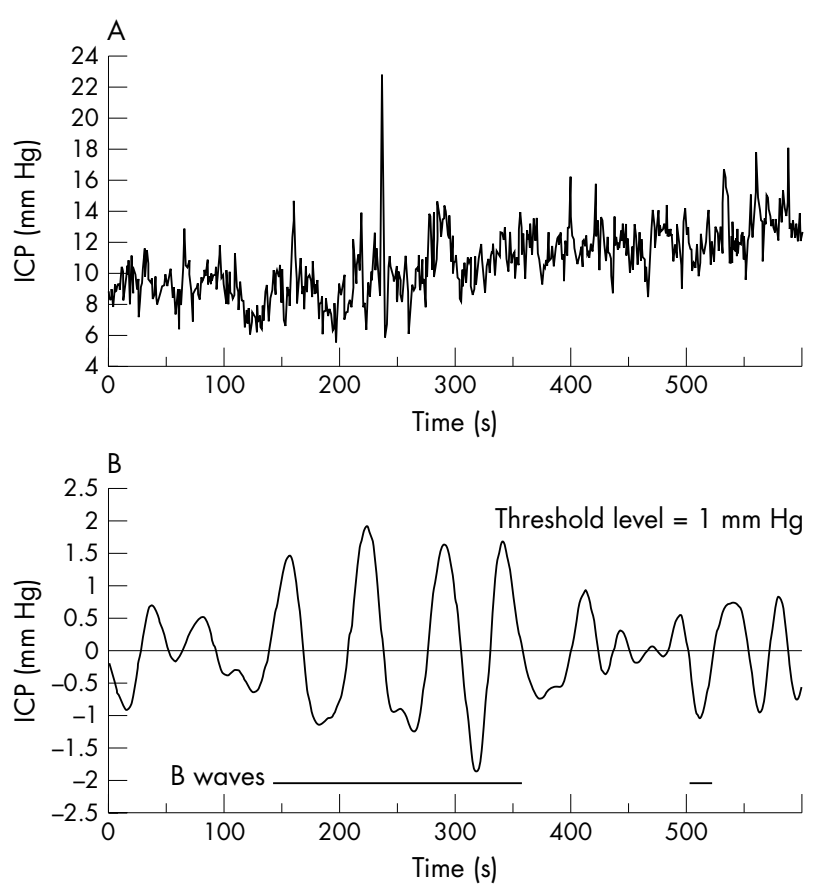

Figure 1 (A) Sample recording of intracranial pressure (ICP) obtained from one patient. (B) Data from (A) filtered using a digital bandpass filter of Butterworth type (fifth order). Cut off frequencies correspond to a wavelength interval of 0.5 to 2 minutes. A computer algorithm for individual wave analysis was used, and sections classified as B waves are marked with a horizontal line. The total $B$ wave incidence was determined as the accumulated time with sections classified as B waves, divided by the total monitoring time. For this sample the proportion of B waves was $39 \%$ at a threshold level of $1.0 \mathrm{~mm} \mathrm{Hg}$.

alertness (daily sleep; reaction time test; impairment of wakefulness), balance (Romberg's test), and social function (living conditions) were calculated from the mean of the standardised variables. In each index, all variables had the same weight. In the postoperative statistics, the mean and standard deviation of the preoperative variables were used in the standardisation. The difference in the preoperative and postoperative values of each index was calculated, and a total index score - the mean of the differences (MoD) - in each patient was determined from the five equally weighted indices as the overall result after shunt surgery. An MoD of more than 0 implied postoperative improvement.

\section{B wave analysis}

The decision to operate was taken before the ICP was recorded, and the recordings were not analysed until after the patients had been re-examined three months after their most recent surgery.

\section{Instruments and data acquisition}

Instruments used for data acquisition were a strain gauge ICP microsensor (Codman ICP MicroSensors ${ }^{\mathrm{TM}}$ ) with a corresponding ventricle catheter, a pressure monitor (Cardiocap II, Datex, Finland), an analogue to digital converter, a data acquisition program (MP100 and Acknowledge ${ }^{\mathrm{TM}}$, Biopac Systems Inc, Goleta, California, USA), and a personal computer. The data acquisition system was thoroughly tested for calibration errors and drift. ICP data were collected at 50 $\mathrm{Hz}$ (50 samples/second).

\section{ICP recording}

The ICP recording was started the day before treatment, using an intraventricular pressure sensor. The ventricular catheter was fixed in the burr hole with a silicone plug and the burr hole was sealed with Tisseel ${ }^{\circledR}$ to prevent leakage of CSF. The recording continued for 17 to 26 hours. The patients were under continuous observation, and their activity, awake or sleeping, and body positions were documented at least every 10 minutes. ${ }^{21}$ The patients could move freely in bed, sit in a chair, or stand beside the bed and were disconnected from the ICP monitor only during toilet visits. These observations were used to divide the ICP recording into periods of sleep and wakefulness. Immediately before the operation the sensors were removed and tested for zero level.

\section{Data analysis}

Basic extraction of ICP data was done with the computer software Acknowledge ${ }^{\mathrm{TM}}$ 3.2. The $\mathrm{B}$ wave frequency was determined by computer software as described by Eklund et al. ${ }^{11}$ The algorithm is based on an individual wave analysis, which considers every waveform with a wavelength of 0.5 to 2 minutes and an amplitude of at least a predefined threshold value $(0.5,0.75,1.0,1.5,2.0,3.0$, and 5.0 $\mathrm{mm} \mathrm{Hg}$ ) as a B wave (fig 1A). A filter of Butterworth type (fifth order) was applied to filter out the wavelength interval of interest (fig 1B), and a waveform was classified as a $\mathrm{B}$ wave if the absolute value of its peak or trough was at least as large as the threshold value. A waveform was considered as a new wave when it passed the zero pressure level. The total B wave incidence was determined as the amount of $\mathrm{B}$ wave time divided by the total monitoring time (\% B waves). The ICP recordings were analysed separately during sleep, wakefulness, and total monitoring time for all patients.

\section{Statistics}

Descriptive statistics were generated and the Mann-Whitney $\mathrm{U}$ and Spearman rank order tests were used for group comparisons and correlation analyses. No corrections for multiple comparisons were done. A paired test (Wilcoxon) was used for intraindividual analyses.

\section{RESULTS}

\section{Postoperative outcome}

Three months after surgery, 45 of the patients $(82 \%)$ had improved, four had deteriorated, and six were unchanged (table 1). The improvement was similar in the non-communicating and the NPH groups (table 1).

Twenty one patients with non-communicating hydrocephalus underwent a third ventriculostomy and eight received a CSF shunt. Owing to an insufficient clinical effect of the ventriculostomy, 10 patients later underwent shunt surgery. One patient, who had received a CSF shunt, had the shunt removed because of infection and later underwent a third ventriculostomy. There were six shunt revisions-three because of shunt infection, two for obstruction of the abdominal catheter, and one because of local abdominal pain.

\section{B waves}

The percentage of $\mathrm{B}$ waves decreased with increasing amplitude thresholds: from $85 \%$ of the time with an amplitude of $0.5 \mathrm{~mm} \mathrm{Hg}$ to $5 \%$ with an amplitude of $5 \mathrm{~mm} \mathrm{Hg}$ (fig 2).

The thresholds 1.0 and $1.5 \mathrm{~mm} \mathrm{Hg}$ most effectively separated the patients into different levels of B wave activity with distributions closest to the normal distribution (fig 2), and the threshold $1.0 \mathrm{~mm} \mathrm{Hg}$ analysis also showed the highest correlation coefficients with outcome. Therefore the results below relate to a threshold of $1.0 \mathrm{~mm} \mathrm{Hg}$.

There was no correlation between overall improvement after surgery and the total percentage of B waves (fig 3). A 

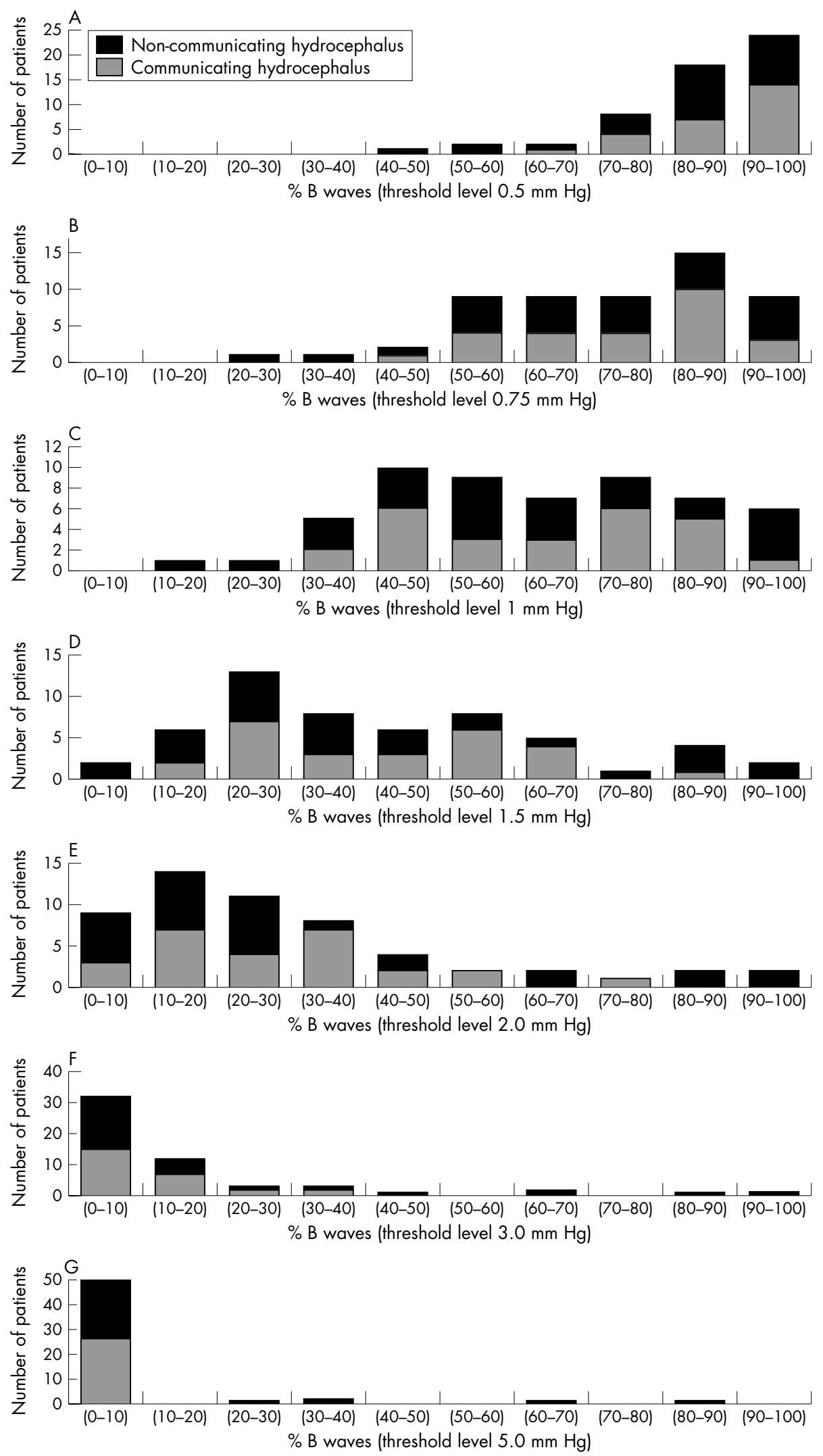

Figure 2 Distribution of B wave activity, estimated as the percentage of total monitoring time (\% B waves) during sleep, in 29 patients with noncommunicating hydrocephalus and 26 with normal pressure hydrocephalus (NPH). Patients with non-communicating hydrocephalus had the same percentage of $\mathrm{B}$ waves as patients with $\mathrm{NPH}$. 


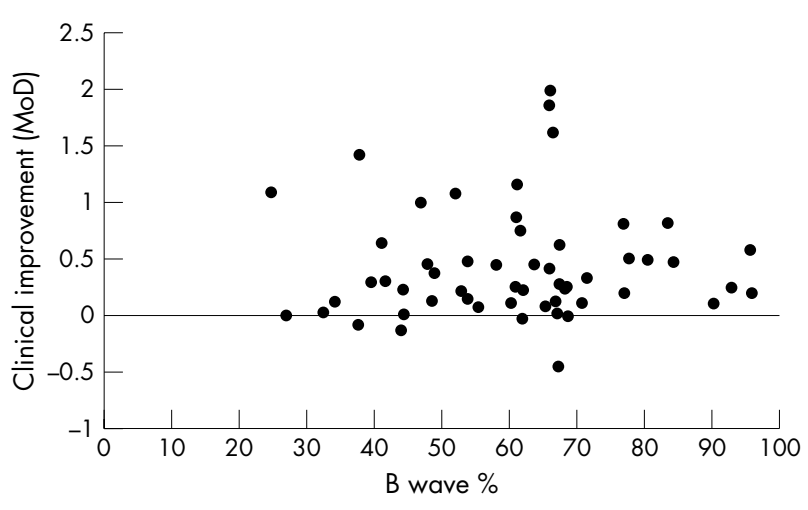

Figure 3 The correlation between total B wave activity at an amplitude threshold of $1.0 \mathrm{~mm} \mathrm{Hg}$ and the clinical outcome, expressed as mean of differences $(\mathrm{MoD})$ between preoperative and postoperative scores on four clinical indices.

weak correlation $(r=0.39, \mathrm{p}=0.04)$ was found between improvement and percentage of B waves during sleep.

In patients with non-communicating hydrocephalus, the total percentage of $\mathrm{B}$ waves correlated with improvement in psychometric performance, and percentage of $\mathrm{B}$ waves during sleep correlated with the overall improvement $(r=0.39, \mathrm{p}=0.04)$ and the improvement in psychometric performance $(r=0.46, \mathrm{p}=0.01)$.

In patients with NPH, no significant correlations were found between the percentage of B waves and any functional index. The percentage of B waves was the same during sleep and wakefulness at all amplitude thresholds (fig 4). Patients with NPH had the same percentage of B waves as patients with non-communicating hydrocephalus (fig 2). ICP correlated positively with the percentage of $\mathrm{B}$ waves at all threshold levels, with correlation coefficients ranging between 0.47 and $0.33(\mathrm{p}<0.002)$.

\section{DISCUSSION}

B waves occurred frequently in our 55 patients with hydrocephalus, but there was no linear correlation between improvement after surgery and the overall percentage of $\mathrm{B}$ waves. This suggests that $\mathrm{B}$ waves are a physiological phenomenon related to the state of hydrocephalus, but are not strongly related to mechanisms that determinate the degree of postsurgical improvement.

Lundberg attributed the origin of the rhythmic B waves to the Cheyne-Stokes respiration in his non-intubated patients, with concomitant increases in $\mathrm{PCO}_{2}{ }^{1}$ Later, $\mathrm{B}$ waves were also seen in ventilated patients, and Venes ${ }^{22}$ suggested an autonomic brain stem rhythm as the direct pacemaker of ICP fluctuations with simultaneous vascular oscillations. Magnaes suggested that B waves were generated by changes in intracranial blood volume reflecting blood pressure waves and brain autoregulation. ${ }^{23} 24$

\section{Predictive value of $B$ waves}

B waves are seen in healthy individuals, ${ }^{8}$ in traumatic brain injury, ${ }^{25}$ and in other brain disorders, ${ }^{26}$ and are very frequent in hydrocephalus, ${ }^{5610}$ as also shown in this study. The proportion of B waves in our patients varied from $24 \%$ to $96 \%$ for the $1.0 \mathrm{~mm} \mathrm{Hg}$ threshold level.

As B waves are a normal phenomenon seen in healthy individuals, only the proportion of $\mathrm{B}$ waves present can be regarded as diagnostically important. Long term sampling of ICP from healthy individuals cannot be done for ethical reasons, and the true predictive value of $\mathrm{B}$ waves in hydrocephalic patients is therefore difficult to estimate.

In our patients, B wave analysis predicted surgical outcome, dichotomised as improved/not improved, with a sensitivity of 0.78 and a specificity of 0.60 with the threshold of $1.0 \mathrm{~mm} \mathrm{Hg}$. The positive predictive value was 0.90 and the negative predictive value was 0.38 . These results are, however, to be expected when analysing a group of patients in whom $82 \%$ are improved by the procedure and where the analysed predictor is an associated phenomenon, as it obviously is in hydrocephalus. If the positive predictive value of having B waves for more than $50 \%$ of the time in this group was determined by chance only, it would be 0.82 .

Physiologically, an abrupt increase in ICP (B wave) caused by an increase in arterial intracranial blood volume can be compensated by an adjustment of arterial blood pressure or oxygen extraction, an increased outflow of venous blood into the venous system, or an increased outflow of CSF into the spinal subarachnoid space. Disturbances of either vascular or CSF mechanisms might be the reason for the high proportion of B waves in hydrocephalus.

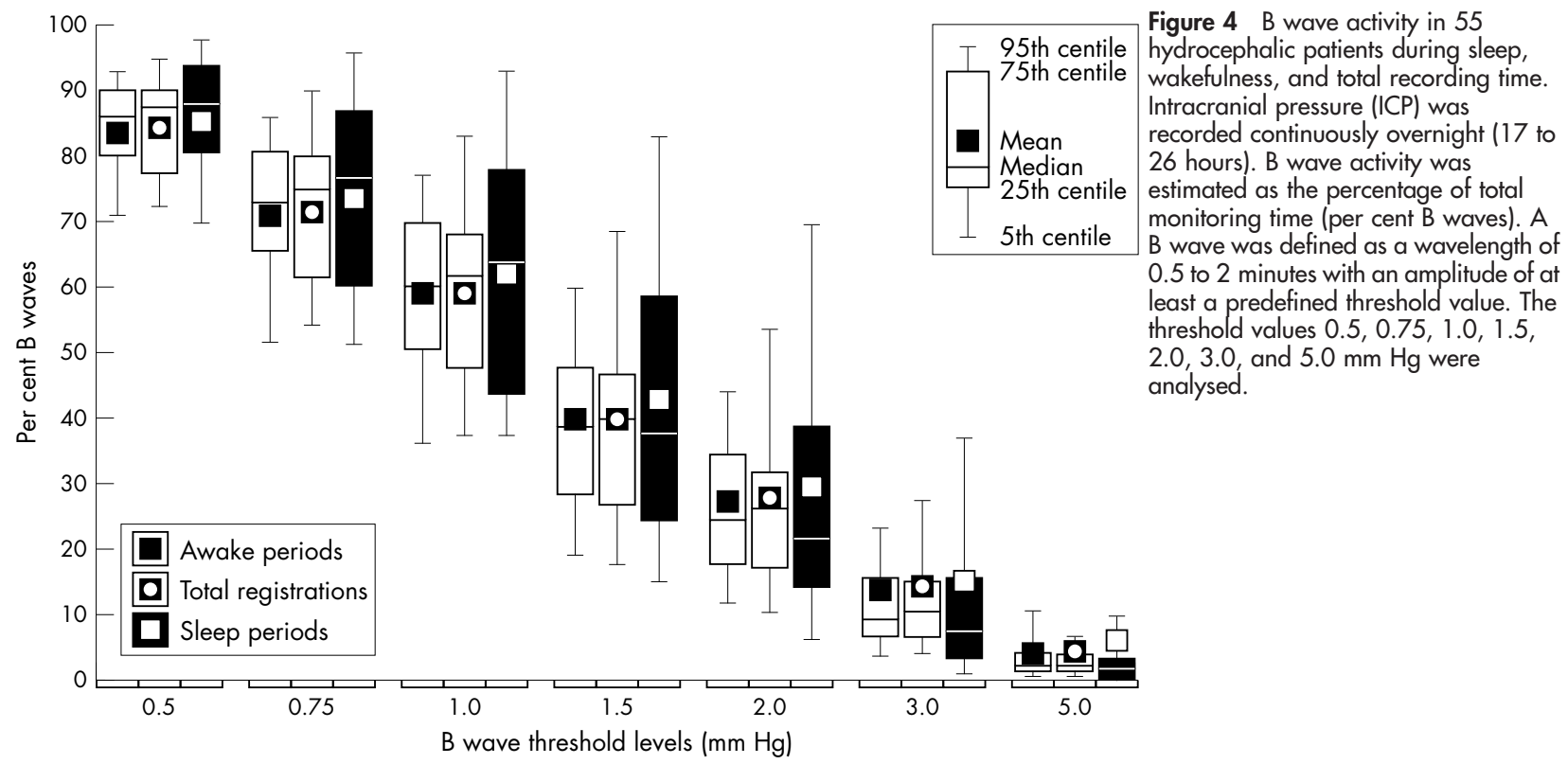


Resistance to CSF outflow ( $\mathrm{R}_{\text {out }}$ ) is typically disturbed in hydrocephalic patients, which could explain the high $\mathrm{B}$ wave frequency seen in this group. A high correlation ${ }^{27}{ }^{28}$ between the amount of $\mathrm{B}$ wave activity and $\mathrm{R}_{\text {out }}$ has been described, but also weak correlations that only exist at high pressure levels. ${ }^{29} \mathrm{~A}$ recent study indicates that the proportion of $\mathrm{B}$ waves is more related to the elastance of the cranio-spinal system. ${ }^{30}$

A major advantage of our computerised method is that it identifies B waves according to a strict definition and is not subject to investigator bias. The method used in this study was based on the criteria used in traditional visual interpretation, and has previously been shown to correlate with visual interpretation. ${ }^{11}$ B wave analysis has been proposed as a reliable diagnostic test for hydrocephalus, but the significance of $\mathrm{B}$ waves remains unclear. ${ }^{31}$ The lack of a significant correlation between outcome after shunt surgery and the objectively determined overall B wave activity seen in this study, which included rather a large number of patients, does not support any strong relation.

\section{B waves during sleep}

Krauss et al showed that there is a relation between the relative frequency, absolute amplitude, wavelength, and morphology of $\mathrm{B}$ waves and different sleep stages. ${ }^{32}$ The relative proportion of $\mathrm{B}$ waves was higher during REM sleep and sleep stage 2 compared with wakefulness, and the absolute amplitude was higher during REM sleep than during wakefulness. ${ }^{32}$ We did not analyse sleep stages, but we carefully observed whether the patients were asleep or awake. Our finding of a correlation between overall improvement and the proportion of $\mathrm{B}$ waves during sleep supports the importance of $\mathrm{B}$ wave analysis during sleep stages, and further studies on B waves as a predictor might focus on B waves during sleep. However, we found no differences in the proportion of $\mathrm{B}$ waves during sleep or wakefulness at any of the thresholds. An increase in B wave activity at night might be expected, as CSF production has a nightly peak at approximately 2 am, when production is approximately twice the daytime values. ${ }^{33}$

\section{Communicating and non-communicating hydrocephalus}

There are differences in CSF dynamics between communicating and non-communicating hydrocephalus which might be reflected by differences in $\mathrm{B}$ wave patterns. We found no differences between the two groups, but this finding might be influenced by the significant age difference between them. If it is accepted that $\mathrm{B}$ waves are related to changes in intracranial blood volume, then recent studies showing that there is no transmantle pressure gradient, ${ }^{21}$ and that $R_{\text {out }}$ is the same in the ventricular system as in the subarachnoid space in non-communicating hydrocephalus, ${ }^{15}$ support our findings.

\section{Conclusions}

B waves are a commonly observed in hydrocephalus, but only weakly related to the degree of post-surgical improvement. The proportion of B waves was the same during sleep and wakefulness, and patients with NPH had the same proportion of $\mathrm{B}$ waves as the non-communicating patients.

\section{Authors' affiliations}

H Stephensen, M Tisell, C Wikkelsö, Hydrocephalus Research Unit, Institute of Clinical Neuroscience, Sahlgrenska University Hospital, Göteborg University, Göteborg, Sweden

N Andersson, A Eklund, Department of Biomedical Engineering and Informatics, University of Umeå, Umeå, Sweden

J Malm, Department of Clinical Neuroscience, University of Umeå Competing interests: none declared

\section{REFERENCES}

1 Lundberg N. Continuous recording and control of ventricular fluid pressure in neurosurgical practice. Acta Psychiatr Neurol Scand, 1960;36:1-193.

2 Auer LM, Sayama I. Intracranial pressure oscillations (B-waves) caused by oscillations in cerebrovascular volume. Acta Neurochir 1983;68:93-100.

3 Lang EW, Diehl RR, Timmermann L, et al. Spontaneous oscillations of arterial blood pressure, cerebral and peripheral blood flow in healthy and comatose subjects. Neurol Res 1999;21:665-9.

4 Droste DW, Krauss JK. Intracranial pressure B-waves precede corresponding arterial blood pressure oscillations in patients with suspected normal pressure hydrocephalus. Neurol Res 1999;21:627-30.

5 Crockard HA, Hanlon K, Duda EE, et al. Hydrocephalus as a cause of dementia: evaluation by computerised tomography and intracranial pressure monitoring. J Neurol Neurosurg Psychiatry 1977;40:736-40.

6 Borgesen SE, Gjerris F. The predictive value of conductance to outflow of CSF in normal pressure hydrocephalus. Brain 1982;105:65-86.

7 Cardoso ER, Piatek D, Del Bigio MR, et al. Quantification of abnormal intracranial pressure waves and isotope cisternography for diagnosis of occult communicating hydrocephalus. Surg Neurol 1989;31:20-7.

8 Mautner D, Dirnagl U, Haber R, et al. B-waves in healthy persons. Berlin: Springer, 1989

9 Symon L, Dorsch NW. Use of long-term intracranial pressure measurement to assess hydrocephalic patients prior to shunt surgery. J Neurosurg 1975:42:258-73

10 Pickard JD, Teasdale G, Matheson M, et al. Intraventricular pressure waves the best predictive test for shunting in normal pressure hydrocephalus. Berlin: Springer, 1980

11 Eklund A, Agren-Wilsson A, Andersson N, et al. Two computerized methods used to analyze intracranial pressure $B$ waves: comparison with traditional visual interpretation. J Neurosurg 2001;94:392-6.

12 Boon AJW. The Dutch normal pressure hydrocephalus study, Rotterdam: Erasmus University Rotterdam, 1999. (PhD Thesis.)

13 Larsson A, Arlig A, Bergh AC, et al. Quantitative SPECT cisternography in normal pressure hydrocephalus. Acta Neurol Scand 1994;90:190-6.

14 Tisell M, Almstrom O, Stephensen H, et al. How effective is endoscopic third ventriculostomy in treating adult hydrocephalus caused by primary aqueductal stenosis? Neurosurgery. 2000;46: 104-10; discussion, 110-11).

15 Tisell $M$, Edsbagge $M$, Stephensen $H$, et al. Elastance correlates with outcome after endoscopic third ventriculostomy in adults with hydrocephalus caused by primary aqueductal stenosis. Neurosurgery 2002;50:70-7.

16 Wikkelso C, Andersson H, Lindberg S, et al. "Shuntography" - a radionuclide scanning method for evaluation of cerebrospinal fluid shunt patency. Nucl Med Commun 1983:4:88-93.

17 Larsson A, Wikkelso C, Bilting M, et al. Clinical parameters in 74 consecutive patients shunt operated for normal pressure hydrocephalus. Acta Neurol Scand 1991;84:475-82.

18 Blomsterwall E, Bilting M, Stephensen $\mathrm{H}$, et al. Gait abnormality is not the only motor disturbance in normal pressure hydrocephalus. Scand J Rehabil Med 1995;27:205-9.

19 Tisell $M$, Tullberg $M$, Hellstrom $P$, et al. Neurological symptoms and signs in adult aqueductal stenosis. Acta Neurol Scand 2003;107:1-7.

20 Tisell M, Tullberg M, Mansson J-E, et al. Differences in cerebrospinal fluid dynamics do not affect the levels of biochemical markers in ventricular CSF from patients with aqueductal stenosis and idiopathic normal pressure hydrocephalus. Eur J Neurol 2004;11:17-23.

21 Stephensen $\mathbf{H}$, Tisell $M$, Wikkelso $C$. There is no transmantle pressure gradient in communicating or noncommunicating hydrocephalus. Neurosurgery 2002;50:763-71; discussion, 771-3.

22 Venes JL. B waves - a reflection of cardiorespiratory or cerebral nervous systems rhythm? Childs Brain 1979;5:352-60.

23 Magnaes B. Body position and cerebrospinal fluid pressure. Part 2. Clinical studies on orthostatic pressure and the hydrostatic indifferent point. J Neurosurg 1976;44:698-705.

24 Magnaes B. Body position and cerebrospinal fluid pressure. Part 1. Clinical studies on the effect of rapid postural changes. J Neurosurg 1976:44:687-97.

25 Czosnyka M, Smielewski P, Kirkpatrick P, et al. Continuous assessment of the cerebral vasomotor reactivity in head injury. Neurosurgery 1997;41:11-17; discussion, 17-19.

26 Droste DW, Krauss JK. Oscillations of cerebrospinal fluid pressure in nonhydrocephalic persons. Neurol Res 1997;19:135-8.

27 Gjerris F, Borgesen SE, Sorensen PS, et al. Resistance to cerebrospinal fluid outflow and intracranial pressure in patients with hydrocephalus after subarachnoid haemorrhage. Acta Neurochir (Wien) 1987;88:79-86.

28 Bech RA, Juhler M, Waldemar G, et al. Frontal brain and leptomeningeal biopsy specimens correlated with cerebrospinal fluid oufflow resistance and $B$ wave activity in patients suspected of normal-pressure hydrocephalus. Neurosurgery 1997;40:497-502.

29 Czosnyka ZH, Czosnyka M, Whiffield PC, et al. Cerebral autoregulation among patients with symptoms of hydrocephalus. Neurosurgery 2002;50:526-32; discussion, 532-3.

30 Lenfeldt N, Andersson N, Agren-Wilsson A, et al. CSF pulse pressure method: a possible substitute of the B-wave examination. J Neurosurg 2004;101:949-50.

31 Vanneste JA. Diagnosis and management of normal-pressure hydrocephalus. J Neurol 2000;247:5-14.

32 Krauss JK, Droste DW, Bohus $M$, et al. The relation of intracranial pressure Bwaves to different sleep stages in patients with suspected normal pressure hydrocephalus. Acta Neurochir (Wien) 1995;136:195-203.

33 Nilsson C, Stahlberg F, Thomsen C, et al. Circadian variation in human cerebrospinal fluid production measured by magnetic resonance imaging. Am J Physiol 1992;262:R20-4. 